\title{
Functional Bakery Products in the Nutrition of Athletes
}

\author{
Shepeleva N.P. ${ }^{1,{ }^{*}}$ Shkaeva N.A. ${ }^{1}$ Shepelev S.D. ${ }^{2}$ \\ ${ }^{1}$ South Ural State University, Institute of Sports, Tourism and Service, 76, Lenina ave., Chelyabinsk, 454080, Russia \\ ${ }^{2}$ Institute of agricultural engineering, South Ural Agricultural University, 75, Lenina ave., Chelyabinsk, 454080, Russia \\ "Corresponding author. Email: shepeleva2@yandex.ru
}

\begin{abstract}
This article is devoted to the study of the use of non-traditional types of raw materials - composite mixtures of wheat flour, flax and buckwheat flour - in the production of functional bakery products intended for athletes. According to the results of the experiments, the recipes of bakery products from a mixture of wheat-flax and wheat-buckwheat flour were determined, the main modes of the technological process were established. The results of research showed that when baking bakery products with the addition of flax and buckwheat at the selected ratios, the rheological properties of the test and the main indicators of the product quality are not inferior to the control sample or even have higher indicators. At the same time, the quality of finished product is improved with an increase in the nutritional value of this product, enrichment with vegetable protein, biologically active substances and polyunsaturated fatty acids. It is shown that the active ingredients of flax and buckwheat flour can be used to purposefully change the taste, aroma and appearance of bakery products, which allows to enrich and expand the range of products for use in sports nutrition, as well as in everyday life.
\end{abstract}

Keywords: functional bakery, nutrition, athletes technological process

\section{INTRODUCTION}

Nutrition plays a significant role in ensuring the optimal growth and development of a growing organism, its ability to work, helps to adapt to adverse environmental influences, affects functional characteristics, health and life expectancy.

The nature of nutrition affects all the biological characteristics of the human body, primarily its physical and mental ones. Food products are sources of energy; they participate in all metabolic processes and serve as plastic material for building human body tissues [1].

A healthy nutrition policy provides for the satisfaction of the physiological needs of the human body in nutrients and fulfills preventive and therapeutic goals. Over the years, the priority in bakery production has been the development of bakery products with low energy value, but with a high content of micro- and macronutrients [2].

A well-chosen diet is an important part of training athletes, and only those athletes who pay special attention to their nutrition are able to improve their physical performance without harm to the body [3].

In the modern world, sports nutrition is very important, which is based on the use of foods high in protein, vitamins, minerals and amino acids.
Modern sports are characterized by prolonged intense physical and psycho-emotional stress, frequent stresses, difficult climatic conditions and other factors. Important requirements for the organization of the training process is the competent construction of a diet with the obligatory replenishment of energy, macro- and micronutrients and maintaining the body's water balance $[4,5]$.

\section{RELEVANCE}

An important role in the diet of athletes is played by bread and bakery products using unconventional raw materials. They are the main source of carbohydrates, vitamins and trace elements. This type of product is used in the daily diet, as well as during intense training, gaining muscle mass and following a diet.

The main task for manufacturers of these products is to increase the nutritional value of bakery products, reducing energy and resource costs in production.

Functional raw materials are widely used in the production of functional bakery products. Important advantages of its use are increasing the nutritional value of the finished product, improving the taste and rheological properties.

The nutritional value of bakery products largely depends on the type and grade of flour, recipe components, as well as the humidity of the products. The main indicators 
of the nutritional value of the product is the content of nutrients - proteins, amino acids, carbohydrates, vitamins and minerals [6].

The basis of bakery products is wheat flour, which contains a significant amount of carbohydrates, as well as vegetable proteins.

To improve the taste, nutritional and biological value of bakery products, flaxseed and buckwheat were introduced into wheat flour.

Flaxseed is considered by modern nutritionists as a valuable source of protein, edible oil, soluble and insoluble dietary fiber $[7,8]$.

Proteins of flax seeds in terms of amino acid composition are more complete than proteins of wheat flour and can complement the latter, increasing the value of bakery products [9].

Flax seeds contain components that can protect the body from diseases of the cardiovascular system and gastrointestinal tract as well as oncology.

Of particular interest for the production of sports nutrition products is flax flour - the result of grinding flax seeds and further degreasing. Flaxseed flour contains from 12 to $20 \%$ fat, of which $75 \%$ is omega- $6,15 \%$ is omega- 9 and at least $8 \%$ is omega-3, as well as $40 \%$ dietary fiber, $30 \%$ - protein and $38 \%$ - carbohydrates. It is rich in vitamins A, E, B1, B2, B5, B6, folic acid, antioxidants and trace elements.

Buckwheat is famous for its beneficial properties. The flour obtained from buckwheat grains is rich in vitamins A, group B, E, PP, and minerals. However, buckwheat flour bread does not contain gluten, so it is included in the diet of people allergic to this type of protein. Buckwheat bread is indispensable during the gluten-free diet as a safe and tasty alternative to conventional flour products. Based on it, the so-called fitness is baked - bread intended for those involved in sports $[10,11]$.

\section{MATERIALS AND RESEARCH METHODS}

For the experiment, the recipe was calculated on the basis of a unified recipe for baked bread.

As the object of study, we selected bakery products from wheat flour, as well as wheat flour with the addition of flax and buckwheat. The control was bread made from wheat flour.

For the samples with partial replacement of wheat flour by experiment, the most suitable ratios were selected: the composite mixture of wheat: flax - 90\%: 10\% (sample 1); and for wheat: buckwheat flour, the optimal value is $85 \%$ : $15 \%$ (sample 2).

The bakery product recipe is presented in table 1 .

An unpaired method of dough preparation was used in the work. Samples were baked at 180 degrees for 45 minutes. Photos of the samples are presented in Figure 1.

As you know, the introduction of additional ingredients in the preparation of the test significantly affects the rheological indicators. In this paper, we study the effect of flax and buckwheat flour on the rheological properties of the dough.

To study the effect of adding alternative types of flour to the bakery recipe, quality indicators were determined: alkalinity, mass fraction of moisture, total sugar, ash, wettability and specific volume.

Table 1. The recipe of samples of bakery products

\begin{tabular}{llll}
\hline $\begin{array}{l}\text { Raw material consumption per 100 g of } \\
\text { the finished product, } \mathrm{g}\end{array}$ & Control & Sample $\mathbf{1}$ & Sample 2 \\
\hline Premium wheat flour & 60.0 & 54.0 & 51.0 \\
\hline Flax flour & 0.00 & 6.0 & 0.00 \\
\hline Buckwheat Flour & 0.00 & 0.00 & 9.0 \\
\hline Sugar & 2.0 & 2.0 & 2.0 \\
\hline Salt & 3.0 & 3.0 & 3.0 \\
\hline Vegetable oil & 10.0 & 10.0 & 10.0 \\
\hline Yeast & 2.0 & 2.0 & 2.0 \\
\hline
\end{tabular}


Control

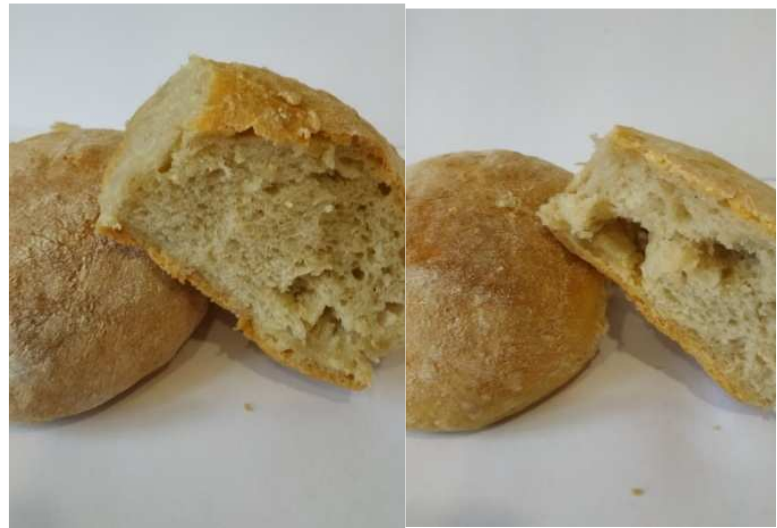

Sample 2

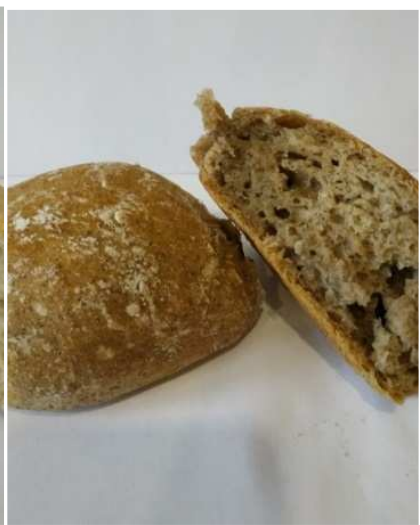

Figure 1. Appearance of the samples of bakery products

Table 2. Comparative analysis of the resulting samples

\begin{tabular}{llll}
\hline Indicator & Control & Sample 1 & Sample 2 \\
\hline alkalinity, grad & 1.7 & 2.5 & 1.8 \\
\hline mass fraction of moisture, \% & 7.0 & 8.0 & 7.0 \\
\hline mass fraction of total sugar, \% & 38.0 & 29.0 & 29.0 \\
\hline mass fraction of ash, \% & 0.06 & 0.07 & 0.07 \\
\hline wetness, \% & 115.0 & 114.0 & 110.0 \\
\hline specific volume, $\mathrm{cm}^{3} / \mathrm{g}$ & 3.2 & 2.5 & 1.53 \\
\hline
\end{tabular}

Alkalinity was determined by titration, which is based on the neutralization of alkali contained in the sample. Mass fraction of moisture was determined by drying. The mass fraction of total sugar was determined using the iodometric method. The mass fraction of ash was determined by the method of burning the product. The ability to determine wetness is based on the ability of bakery products to swell in water. The specific volume was determined by the density and mass of the samples. Based on the calculated numerical values, Table 2 was compiled for comparison and analysis of quality indicators of the samples of bakery products.

\section{RESULTS AND DISCUSSION}

Analysis of Table 2 showed that the minimum alkalinity was in the samples of bakery products with the addition of buckwheat flour, and the maximum - with the addition of flax flour. The mass fraction of moisture in the control sample and the sample with the addition of buckwheat flour is equivalent, and in the sample with linseed flour it is $1 \%$ higher. The proportion of total sugar in the product samples with the addition of buckwheat and flax flour is lower than that in the control sample by $9 \%$. The mass fraction of ash is approximately the same in all the samples presented. The wettability index is minimal in the sample with the addition of buckwheat flour, and in the control we observe the maximum values. The specific volume in the sample with linseed flour is higher than that in the sample with the addition of buckwheat flour.

In addition to physic-chemical indicators, organoleptic quality indicators of the bakery products with the addition of flax and buckwheat flour were determined in this work. Organoleptic quality indicators of the bakery products are presented in table 3.

During the organoleptic analysis of the resulting samples of the bakery products with the addition of flax 
flour, the correct shape of the product is noted, the surface is smooth, there are neither cracks nor tears, no obvious discoloration was noted; the color of the peel was pale yellow. The crumb of bread made from wheat flour and flaxseed was approximately the same in mass. The characteristic smell and taste were absent.

When studying the resulting product samples with the addition of buckwheat flour, a change in the color of the crust and the color of the crumb was revealed. The color of the crust of the products became darker, and the whiteness of the crumb decreased in the direction of a brown hue as compared to the control sample. The crumb of wheat flour was lighter than the crumb of the samples with buckwheat flour. In addition, the buckwheat flour sample developed a characteristic buckwheat smell and aftertaste.

Table 3. Organoleptic quality indicators of the bakery products

\begin{tabular}{cccc}
\hline $\begin{array}{c}\text { Quality indicators of } \\
\text { the bakery products }\end{array}$ & Control & Sample 1 & Sample 2 \\
\hline Appearance & $\begin{array}{c}\text { Corresponds to the } \\
\text { type of product }\end{array}$ & $\begin{array}{c}\text { The form is correct, corresponds to the } \\
\text { form in which the baking was made. }\end{array}$ \\
\cline { 2 - 4 } Shape and surface & $\begin{array}{c}\text { The surface is } \\
\text { smooth. }\end{array}$ & $\begin{array}{c}\text { The surface is quite smooth, neither } \\
\text { cracks nor tears. }\end{array}$ \\
\hline Peel color & Light brown & $\begin{array}{c}\text { Pale yellow, } \\
\text { closer to light } \\
\text { brown. }\end{array}$ & brown \\
\hline $\begin{array}{c}\text { The state of the } \\
\text { crumb (baked, prom, } \\
\text { porosity) }\end{array}$ & Baked, not moist to the touch, without traces of \\
impermeability & \\
\hline Taste & Peculiar to a product of this type, \\
without extraneous taste & $\begin{array}{c}\text { Peculiar to a } \\
\text { product of this } \\
\text { type, with a taste } \\
\text { of additive }\end{array}$ \\
& & $\begin{array}{c}\text { Peculiar to a } \\
\text { product of this } \\
\text { type, with odor } \\
\text { additives }\end{array}$ \\
& & Peculiar to a product of this type, \\
without odor &
\end{tabular}

\section{CONCLUSION}

As a result of the experiments, we can conclude:

1. It was experimentally established that when baking bakery products with the addition of flax and buckwheat at the selected ratios, the rheological properties of the dough and the main indicators of product quality are not inferior to the control sample or even have higher indicators. This is especially important, since the goal was to obtain a functional product intended for athletes nutrition.

2. When using a composite mixture with the use of flax and buckwheat flour, the quality of the finished products improves with the nutritional value of this product, enrichment with vegetable protein, biologically active substances and polyunsaturated fatty acids.

3 . The calculation of the nutritional value of the finished product showed that with the introduction of flax flour into the bakery recipe, the protein content increased by $16 \%$, fat by $32 \%$, dietary fiber by $19 \%$ compared with the control sample $[12,13]$.

4. With the introduction of buckwheat flour in the bakery formulation, the protein content increased by $12 \%$, fat by $28 \%$ and dietary fiber by $21 \%$ compared with the control sample.

5 . The daily requirement is calculated due to the use of the developed bakery products. It has been established that due to the consumption of $300 \mathrm{~g}$ of the products, the daily 
need for protein is covered by $12-16 \%$, in dietary fiber - by $19-21 \%$, in fats - by $28-32 \%$.

Thus, the development of new recipes for bakery products, the introduction of non-traditional types of flour into the dough is very relevant and important for functional and sports nutrition.

The obtained data form the basis of the methodology for creating bakery products for power sports athletes.

\section{REFERENCES}

[1] O.D. Sergazieva, E.V. Pershina, O.N. Krivonos. 2019 Application of the principles of healthy nutrition in the network of fast food service enterprises of Astrakhan in: Proceedings of the Voronezh State University of Engineering Technologies 81(1) pp. 247-251.

[2] N.V. Sokol, N.S. Khramova, O.P. Gaidukova. Nontraditional raw materials in the production of functional bread Bakery of Russia 1 (2011) 16.

[3] V.G. Lobanov, G.I. Kasyanov, E.A. Mazurenko. Features of the diet of athletes playing sports Proceedings of the Voronezh State University of Engineering Technologies 81(1) (2019) 160-167.

[4] S.A. Polievsky. Fundamentals of individual and collective nutrition of athletes, Moscow, Physical Culture and Sports, 2005.
[5] V.M. Schepina, et al. Assessment of the adaptive capabilities of athletes Theory and Practice of Phys. culture 1 (2009) 27-30.

[6] I. Minevich, V. Zubtsov, T. Tsyganova. Use of flax seeds in bakery Bakery products 3 (2008) 38 .

[7] L.E. Enzifst, M.E. Bveo. Flaxseed (Linseed) fiber nutritional and culinary uses - a review Food New Zealand April/May (2014) 26-28.

[8] P.M. Ganorkar, R.K. Jain. Flaxseed - a nutritional punch International Food Research journal 20(2) (2013) 519-525.

[9] V.A. Zubtsov, I.E. Minevich. Biological and physicochemical principles of the use of flax flour for the development of bakery products Storage and processing of agricultural raw materials 3 31-34.

[10] V.A. Meshcheryakova. The correct choice of bread for the prevention of various diseases and with dietetic nutrition Bread business 1(15) (2003) 23-25.

[11] A.N. Zenkova, I.A. Pankratov, O. V. Polytukha. Buckwheat - a product of high nutritional value Bread products 1 (2013) 42.

[12] A.P. Kosovan, G.F. Dremucheva, R.D. Polandova. Methodical guide to determine the chemical composition and energy value of bakery products, Moscow, Moscow printing house No. 2, 2008.

[13] V.A. Tutelyan. The chemical composition of Russian food products: a reference book, Moscow, DeLi print, 2002. 